I Universidade Federal do Rio de Janeiro (UFRJ), Programa de Pós-Graduação

em Sociologia e Antropologia, Rio de Janeiro, RJ, Brasil

josereginaldo.goncalves@gmail.com

José Reginaldo Santos Gonçalves'

\title{
UM AMIGO DO MUNDO
}

Era hábito dele colocar em contato pessoas muito distanciadas entre si, mas que ele aproximava em função dos interesses intelectuais comuns que ele mesmo percebia com muita sensibilidade. Ele as aproximava e depois, discretamente, se afastava. De forma tal que, mesmo agora, já ausente, permanece como forte referência afetiva e intelectual entre essas pessoas que, por causa dele, tornaram-se, de certa maneira, próximas. Movia-se sempre numa constelação de relações, fazendo mediações, sem que reivindicasse qualquer centralidade. Não precisava. Era daqueles que influem secretamente na vida de muitos. Em termos intelectuais, exercia também com maestria a mediação com os clássicos e com a produção intelectual contemporânea, sempre disposto a oferecer, com extrema generosidade, indicações bibliográficas valiosas, além de sugestões sempre oportunas. Ricardo Augusto Benzaquen de Araújo (I952-2017) desempenhou uma função singular na vida pessoal e intelectual de seus amigos e conhecidos. Essa função dificilmente poderá ser resumida a uma simples apreciação subjetiva, em que, comodamente, diríamos que cada um guardará para si a sua própria e infiel memória. A relatividade dos pontos de vista individuais e coletivos é um fato. Mas, diante dessa multiplicidade, uma pergunta impõe-se: como era possível que esse brilhante intelectual reunisse em torno de si tantas pessoas com posições intelectuais e ideologias políticas, estilos de vida e visões de mundo tão distintas? Onde residia o mistério de seu poder de sedução pessoal e intelectual? Imagino que 
esse poder residisse no modo peculiar com que ele experimentava cotidianamente suas relações com o mundo.

Meu amigo e interlocutor constante, Ricardo deixou-nos no fim da tarde do dia I de fevereiro deste ano de 2017. Lembro quando viemos a nos encontrar casualmente no pátio do Museu Nacional, numa tarde do mês de agosto do ano de 1974, depois de recebermos, com alegria, os resultados da seleção ao programa de mestrado em antropologia social a que havíamos nos submetido: estávamos entre os três primeiros colocados. Não nos conhecíamos até esse momento. Em comum, até então, a paixão pela antropologia, que havíamos recentemente descoberto. Embora tenha passado a vida em departamentos de história e de sociologia, manteve sempre com aquela disciplina uma relação de forte cumplicidade. Ele vinha, desde o início dos anos I970, de uma graduação em história na PUC-Rio; eu, desde a mesma época, de uma graduação em ciências sociais no IFCS/UFRJ. A partir de então, com as naturais variações das relações humanas ao longo do tempo, estivemos muito próximos, nos planos pessoal e intelectual.

Lembro-me da primeira vez que minha mulher e eu visitamos Ricardo no endereço em que veio a residir com sua primeira esposa, a antropóloga Silvana Miceli, na Rua Nina Rodrigues, no Leblon, na segunda metade dos anos 1970. Era uma ensolarada manhã de sábado, e quando chegamos Ricardo atendia um de seus alunos da PUC, onde dava aulas de história. Manhã de praia, para onde muita gente se dirigia àquela hora. Não eram exatamente um dia e hora dos mais adequados para uma reunião de orientação acadêmica. Mas, ao longo de toda a sua vida e mesmo nos seus últimos anos, esse nunca foi um problema para ele. A seus numerosos alunos dedicou-se de forma extremamente generosa, verdade que ressoa de modo carinhoso na memória e nos depoimentos daqueles tantos que com ele conviveram numa sala de aula e estiveram expostos ao seu brilho intelectual.

Ao longo de quatro décadas, tive o privilégio de contar com a sua presença enquanto um amigo muito querido e como uma espécie de consultor seguro em relação aos problemas com que me defrontei em minha vida intelectual e profissional. Jamais convivemos no plano institucional, com exceção do tempo que frequentamos juntos, como alunos, o programa de antropologia social do Museu Nacional. Passei grande parte de minha vida em departamentos de antropologia, no Brasil ou no exterior (como estudante ou como professor); Ricardo, ao longo de sua vida, esteve ligado a diferentes instituições: à PUC-Rio, no Departamento de História, onde iniciou e concluiu sua carreira de professor e pesquisador; ao CPDOC, onde esteve, como pesquisador, nos anos I980; e ao antigo Iuperj, instituição que teve destino ingrato e que afetou gravemente a vida profissional de Ricardo. Em seu desempenho público teve papel notável na consolidação dos estudos de pensamento social no Brasil, que ajudou, com brilhantismo, a transformar numa área extremamente importante na paisagem atual das ciências sociais no Brasil. 
Em seus últimos anos, dedicava-se inteiramente à sua Alma Mater. Pelo que sei, destacou-se por uma admirável lealdade a cada uma dessas instituições. Diferentemente do padrão mais usual, pensava primeiramente na instituição em que trabalhava, apenas secundariamente em sua própria carreira. Esse aspecto foi objeto de constantes comentários, advertências e aconselhamentos dos amigos mais próximos, que viam com preocupação sua excessiva devoção institucional em detrimento de seus próprios interesses intelectuais e profissionais. Mas esses comentários, advertências e aconselhamentos não ressoavam muito fortemente nos seus sentimentos e no seu comportamento cotidiano. Em cada encontro com Ricardo, pude perceber que trazia consigo o envolvimento pessoal em algum imbróglio institucional. Era intensamente atraído por essas situações que eu, ao contrário dele, sempre procurei evitar.

Acredito que cada uma das instituições onde trabalhou beneficiou-se largamente não só de sua competência intelectual, de sua lealdade, assim como de seu notável talento para mediar relações pessoais, complicadas relações institucionais e profissionais. Como uma criatura eminentemente mundana, sentia um ostensivo prazer em operar essas mediações, encontrando saídas sempre suaves para situações de crise institucional. Dizia-me certa vez que sua ambição não era exatamente o poder, mas ser influente. De fato, não lembro de nenhum cargo realmente importante que Ricardo tenha ocupado ao longo de sua vida. Mas sua efetiva e discreta presença era senti$\mathrm{da}$ em qualquer contexto institucional. Como jamais convivi continuamente com ele em uma mesma instituição, como professor ou pesquisador, os que tiveram essa experiência poderão confirmar (ou não) o que digo. Mas, como disse, minha convicção emerge do que ele sempre me trazia em nossos encontros e longas conversas, quando agendava comigo um jantar ou um café, depois de cumprir seus tantos compromissos institucionais, assim como seus não menos numerosos e não menos importantes encontros com amigos, colegas e alunos.

$\mathrm{Na}$ biografia de Ricardo cruzam-se aspectos pessoais e intelectuais numa fascinante alquimia. Era um leitor constante de Georg Simmel (I858I9I8). Sabemos todos da distinção elaborada por esse autor entre "cultura subjetiva" (persönliche Kultur) e "cultura objetiva" (sachliche Kultur). Segundo ele, em decorrência do domínio avassalador desta última (sistemas econômicos, sistemas políticos, legislações, a ciência, as tecnologias, os bens materiais e imateriais que compõem a chamada "civilização"), inibe-se a primeira. A "cultura subjetiva", por sua vez, consiste precisamente na incorporação dos itens que compõem a "cultura objetiva" ao processo de autoaperfeiçoamento, de cultivo individual de uma autoconsciência social e existencial. As tensões que atravessam esse processo geravam o que chamou de "tragédia da cultura". Acreditava Simmel (I988: I77-2I6) que uma das ta- 
refas importantes dos cientistas sociais é mostrar as possibilidades de ressubjetivação da sociedade, apontando as limitações e os riscos impostos a cada um de nós pelo domínio da "cultura objetiva", mostrando que esta, sem o cultivo desse autoaperfeiçoamento e dessa autoconsciência, poderia conduzir-nos tragicamente à barbárie. Ao longo de sua vida, Ricardo combateu cotidianamente esse risco. Ele cultivou esse autoaperfeiçoamento no seu cuidadoso e paciente ofício de intelectual, pesquisador e professor. Mas também na vivência afetiva e bem-humorada de suas relações pessoais. Sua persona coletiva estava de algum modo muito próxima de seu self, do seu 'eu' mais profundo, que dialogavam de modo tenso e chegavam, por vezes, perto do impossível encontro entre aquelas incompatíveis dimensões da cultura moderna. Esse encontro, permanentemente adiado, foi cultivado por ele de forma especial no plano da amizade. Era um artista da amizade. Reconheceu e experimentou como poucos o caráter complexo e indefinível desse sentimento. Não por acaso dedicou, nos últimos anos, suas reflexões a esse tema clássico em autores que foram objeto de seus estudos, notadamente Gilberto Freyre (I900-I987) e Joaquim Nabuco (I849-I9Io). Situava o tema dentro de seu amplo e implícito programa de estudos sobre a história da subjetividade ocidental e buscava nesses autores o modo como, em seus textos, construíam sua noção de subjetividade, sua autoconsciência (Araújo 2004; 2005). Entendendo a história intelectual como uma espécie de "antropologia cultural retrospectiva", na expressão de Stuart Hughes (1975:24) para definir a história, fazia emergir da obra de cada um desses autores categorias de pensamento que pertenciam, de nosso ponto de vista, a um estranho e distante universo social e cultural: o final do século XIX com Nabuco (Araújo 2004: 5-I4); o pensamento integralista de Plínio Salgado no contexto dos anos I920 e I930 (Araújo I987); os mesmos anos 30 do século XX, tal como ressoavam na obra de Gilberto Freyre (Araújo 2005). Um etnógrafo no tempo, exercia uma espécie de olhar distanciado, construindo entre nós e esses autores uma ponte de mão dupla, que nos permitia, ao mesmo tempo, perceber o quanto eram estranhos ao nosso universo social e mental contemporâneo e o quanto podiam parecer incomodamente atuais. Mas, com notável delicadeza explorava as nuanças do pensamento de cada um deles, levando a sério seus respectivos pontos de vista, em nenhum momento reduzindo suas obras à expressão de um contexto social e cultural objetificado.

Seu premiado Guerra e paz: Casa-grande \& senzala e a obra de Gilberto Freyre nos anos 30 representou uma notável renovação nos estudos sobre Gilberto Freyre, autor que, por décadas e décadas, sofreu o veto implícito ou explícito reservado a autores classificados como "reacionários", "de direita", "racistas", e atributos semelhantes. Guerra e paz resgatou um autor genial da recepção medíocre e acusatória. O livro, publicado inicialmente em I993, conheceu uma segunda edição em 2005 e conheceu recentemente uma edição argentina (2017). 
Ao longo das últimas décadas, são inúmeros os estudos sobre esse autor e Gilberto é reconhecido como um grande sociólogo. Mas devo trazer aqui o ponto de vista de quem frequentou uma grande universidade brasileira no início dos anos I970, onde Casa-grande \& senzala (assim como outras obras desse autor) não entrava em nenhuma bibliografia de curso. Devemos seguramente ao livro de Ricardo essa espécie de abertura para os estudos sobre Gilberto Freyre. ${ }^{\mathrm{I}}$

Em seu diálogo com esse autor, ele revelou uma visão heterodoxa do Brasil, só passível de resgate em função da erudição de seu intérprete, que foi buscar na história intelectual as origens de muitas categorias usadas por Gilberto em sua análise da sociedade patriarcal brasileira. Assim foi com a noção de "raça", cujo uso foi qualificado por Ricardo em sua análise de Casa-grande \& senzala. Segundo ele, a concepção de Gilberto distingue-se tanto daquelas de autores cuja noção de raça (baseadas em autores como Agassiz e Gobineau) levavam-nos a ver a miscigenação como um fato negativo e que levaria necessariamente o Brasil ao fracasso diante de qualquer esforço civilizatório; quanto daquelas de autores que, ao avaliarem positivamente a miscigenação, postulavam no entanto o "branqueamento", que levaria a superar os supostos limites biológicos de negros e índios pela supremacia dos brancos. Ambos interpretam negativamente a herança racial: os primeiros julgam tais limites insuperáveis; os segundos acreditam na sua eliminação. Ao apontar a identificação de Gilberto com as teorias neolamarckianas, mostra que:

distinguindo raça de cultura e por isto valorizando em pé de igualdade as contribuições do negro, do português e - em menor escala - do índio, nosso autor ganha forças não só para superar o racismo que vinha ordenando significativamente a produção intelectual brasileira mas também para tentar construir uma outra versão da identidade nacional, em que a obsessão com o progresso e com a razão, com a integração do país na marcha para a civilização, fosse até certo ponto substituída por uma interpretação que desse alguma atenção à híbrida e singular articulação de tradições que aqui se verificou" (Araújo, 2005: 28).

Nessa leitura, as teses de Gilberto parecem na verdade contornar a categoria "raça", tal como aparece entre os que condenam e os que defendem a miscigenação. Em outras palavras, na interpretação de Ricardo, a raça deixa de ser um dado e passa a ser uma categoria e, portanto, variável em termos socioculturais e históricos. Ignorar esse procedimento é abrir as portas para as célebres e fáceis interpretações acusatórias que nos apresentam Gilberto como "racista".

Embora circulasse entre historiadores e sociólogos, repercutia em seu pensamento a tradição antropológica a que fora exposto durante fase decisiva de sua formação intelectual, acreditando, portanto, que a cultura, longe de ser um domínio de princípios e regras abstratas, passava necessariamente pelo corpo e pelos sentimentos de indivíduos concretos, os quais poderiam, criativamente, torná-la singular, construindo ou inventando-a, ao mesmo 
tempo que construíam ou inventavam a si mesmos. Evidentemente, essa visão da cultura funda-se numa possibilidade, numa expectativa, numa espécie de aposta; não se trata exatamente de um fato. Nem todos, infelizmente, podem ser tão criativos quanto Gilberto Freyre ou Joaquim Nabuco. Mas Ricardo exercia com generosidade e otimismo tal expectativa em relação a cada um de seus numerosos amigos e alunos. Frequentador dos clássicos alemães, conhecia e cultivava a chamada Bildung, noção fortemente associada à ideia de "formação" (Bruford, I975). Nessa perspectiva, os indivíduos são vistos como dotados de algumas potencialidades que poderão ser cultivadas (e autocultivadas) ao longo da vida. Essa ideia lhe era muito cara e servia como horizonte nos seus escritos e nas suas relações pessoais e profissionais. Enquanto amigo ou enquanto professor, dedicava-se de modo perene ao interminável ofício da formação. Sem qualquer ostentação ou atitude professoral, cultivou esse valor em sua extensa rede de relações, em que cada um, ao interagir com ele, tinha a chance de se sentir único, um indivíduo singular, criativo, uma vez que ele possuía o poder de nos convencer de nossos melhores atributos intelectuais e éticos e da possibilidade efetiva de desenvolvê-los. Nesse sentido contribuiu, em um sentido amplo, para a formação de muitos daqueles que tiveram o privilégio de com ele conviver. O que não impedia que, privadamente, expressasse com ironia e humor o que intimamente pensava a respeito de cada um deles e de seus respectivos limites intelectuais e éticos.

Era um amigo do mundo. Lembro que, no início dos anos I980, recomendou-me a primeira edição de uma biografia intelectual escrita por Elizabeth Young-Bruehl (1982): Hannah Arendt: for the love of the world. Esse belo título ressoava significativamente nas atitudes pessoais e intelectuais de Ricardo, que foi leitor assíduo de Hannah Arendt. Mas, apesar de seu amor ao mundo, não se sentia inteiramente como parte do tempo que lhe foi concedido viver entre nós. Alguns comentavam que suas análises pareciam partir do passado em direção ao presente. Usava o passado para desestabilizar e iluminar o presente. Seu ritmo muito pessoal ao ler, pensar, escrever, conversar, contrastava fortemente com o tempo vertiginoso que nos vem sendo imposto pelos estritos prazos das agências financiadoras em relação a publicações, defesas de dissertações e teses, conclusão de cursos, etc. Lembro que escreveu muitos dos seus melhores textos à mão e em papel almaço. Numa determinada época, ao concluir seus manuscritos, pedia a alguém para os datilografar. Assim foi com seu Guerra e paz. Ou, mais adiante, para digitar outros originais num computador. Nunca esteve muito à vontade diante da tela de um computador ou de um tablet. Não se sentia confortável dentro do universo contemporâneo dominado pelas novas tecnologias e pelas redes globalizadas de trocas intelectuais. Um jeito gauche de estar no mundo, como ele mesmo gostava de descrever a si mesmo. Esse aspecto define, a meu ver, muito de seu modo de 
pensar e entender a vida intelectual. Acompanhava as novidades, mas sempre com um apurado senso crítico e um contagioso humor, resultado em parte de sua extensa e segura erudição. Embora sempre atualizado com a bibliografia, nunca o surpreendi enfeitiçado por algum autor ou por algum conjunto de categorias recém-chegadas ao nosso universo intelectual.

Soube manter, ao longo da vida, um difícil equilíbrio em suas relações com o mundo. Difícil porque essas relações, no seu caso, eram atravessadas pelo que poderíamos chamar de "excesso". Ao mesmo tempo que convivia bem com os sensíveis prazeres do mundo, gozava diante deste o que Borges (2005: 9I-93), num perfil intelectual de Paul Valéry, chamou de "os lúcidos prazeres do pensamento". Por um lado, um envolvimento fortemente afetivo e sensual com o mundo exterior; por outro, uma atitude estética, o cultivo do mundo interior.

Essa tensão repercutia em algumas de suas leituras, análises, artigos e cursos, especialmente quando voltou seu interesse para a obra de Thomas Mann e a tensão que atravessa a própria noção de Bildung: por um lado, o cuidado com a formação da subjetividade, do mundo interior; por outro, o relativo descaso com o mundo exterior, especialmente a política (Bruford, I975: 226-263). Esse descaso vem a ser problematizado pelo próprio Thomas Mann (2016) em seu romance A montanha mágica, quando aponta a falência da Bildung, em virtude desse distanciamento do mundo (ver também Bruford, I975: 206225; Goldman, I988; Araújo, 2005: 20). No caso de Ricardo, era possível perceber um entendimento crítico dessa noção que, em seu comportamento cotidiano e em seus textos, nunca pareceu dissociado do seu forte interesse pessoal pelo mundo exterior, notadamente o mundo político.

Mas não só o universo da política. No que tange a suas relações sensíveis com o mundo, os amigos, especialmente os mais próximos, conheciam seu notável paladar. Era um amigo constante dos bons pratos. Não deve ter sido difícil para ele surpreender essa dimensão na análise que fez do pensamento de Gilberto Freyre em Casa-grande \& senzala (2004), em que identificou a presença daquela mesma categoria: o "excesso" (Araújo 2005: 54-70). ${ }^{2}$ Sua mãe, a adorável e inesquecível dona Sol, oferecia em sua casa em Petrópolis almoços verdadeiramente pantagruélicos, com pratos e sobremesas que, como diria Eça de Queiroz, "pareciam ter sido feitos no céu". Era, na verdade, a culinária de Manaus, com sua extensa variedade de peixes de água doce (lembro-me de maravilhosos tucunarés e pacus), que ela mandava trazer diretamente de sua cidade natal, servidos com diversos e exóticos molhos. Eram também notáveis a variedade e a quantidade de doces servidos à sobremesa. Recebia todos os convidados com atenção, alegria e generosidade. Só não perdoava aqueles que, por alguma razão - para ela, absolutamente inexplicável! - comiam pouco (do seu ponto de vista, é claro). Não permitia um instante sequer que alguma tigela ficasse vazia sobre a mesa. Ou que algum prato permanecesse vazio nas 
mãos de um convidado. Lembro que, num desses almoços, uma amiga comum, que tinha em altíssima conta o livro de Ricardo sobre Gilberto Freyre, diante daquela farta mesa e da generalizada comilança, sussurrou ao meu lado, numa espécie de iluminação profana: "Agora eu entendi tudo...".

Ainda nessa chave do "excesso", era também perceptível para os amigos e colegas a dedicação obsessiva de Ricardo ao trabalho. Desde que o conheci nos anos I970, jamais abandonou sua rotina de trabalhar até altas horas da madrugada, preparando suas aulas (que os alunos pensavam em gravar para publicação), lendo, tomando notas, atendendo telefonemas, ou, como ele mesmo confessava, assistindo filmes (sem distinção de qualidade) na televisão ou jogos de futebol (torcia pelo Vasco). Era um notívago e costumava ir para a cama quando amanhecia.

Fique claro, no entanto, que sua excessiva dedicação ao trabalho não era regulada por nenhuma espécie de éthos puritano, por nenhuma atitude rigorosa e disciplinadora sobre o mundo, como aquela descrita por Weber (2004) em seu clássico livro. Ao contrário, era, como diria Montaigne (2016: 424) em relação a um autor antigo, "indulgente como a maioria dos homens gordos e alegres". Estava mais próximo do éthos descrito pelo mesmo Weber (1964: 226-249) para os antigos chineses: uma atitude centrada não no disciplinamento rigoroso, mas na adaptabilidade ao mundo, o qual ele via sempre, não abstratamente, segundo determinadas normas, mas em sua concretude e variedade. ${ }^{3} \mathrm{O}$ trabalho era para Ricardo, antes de tudo, fonte de um interminável prazer físico e mental, uma de suas formas sensíveis de estar no mundo, indissociável de sua vida cotidiana. Exercia nessas adaptáveis relações com o mundo uma modalidade de "equilíbrio de antagonismos", para usar uma categoria de Gilberto Freyre (2004: II6), ${ }^{4}$ que lhe era muito cara na análise que empreendeu da obra desse autor (Araújo, 2005: I83-2I2). Uma espécie de instável equilíbrio era o coração de sua vida pessoal, profissional e intelectual. As circunstâncias, os diversos momentos de sua vida ofereceram configurações específicas a essa tensão essencial.

Árdua tarefa, a de falar de alguém que já não fala por si mesmo. Há o risco de sermos parciais e de faltarmos à verdade. Há o risco inevitável de trair aquilo que a pessoa considerava o mais importante. Afinal cabe à própria pessoa narrar a verdade de sua vida. Mas o que está em jogo é mais que isso. É uma dívida que temos não apenas com quem já não mais está entre nós, mas também uma dívida que temos diante de nós mesmos e diante do modo pelo qual escolhemos viver publicamente. Pois se trata precisamente daquilo que valorizamos em nossa vida pessoal, intelectual e institucional. Ao lembrar Ricardo, estamos na verdade assumindo e celebrando os valores e ideais que ele soube representar de modo tão singular. Não exatamente como uma espécie de exemplaridade monumental (nada mais distante da autoimagem de Ricardo!), mas como a memória viva, presente de modo sensível, ain- 
da que inconsciente, no pensamento e nas ações cotidianas daqueles que com ele conviveram e cultivaram alguma afinidade existencial.

Os futuros historiadores, ao estudarem a sociedade brasileira atual, provavelmente terão sua atenção despertada pelas atitudes cotidianas de decepção e desesperança diante da vida, especialmente da vida cultural e política. De fato, numa paisagem intelectual tão pobre e desalentadora quanto a que nos assombra atualmente; diante das recentes e assustadoras mudanças políticas que o país atravessa; a morte de Ricardo nos faz pensar que nossa tarefa como intelectuais, professores, pesquisadores tornou-se bem mais difícil. Perdemos todos um notável ser humano que soube viver, até as últimas consequências, com inteligência, imaginação, tolerância, elegância e humor, os desafios, os perigos e as perenes decepções a que se expõem todos aqueles que pretendem levar a sério a vida intelectual no Brasil. Mas nem por isso precisamos facilitar a tarefa daqueles futuros historiadores e fingir que somos unânimes naquelas atitudes negativas diante da vida. Afinal, ante os imperativos do dia, continuaremos a pensar, a escrever, a formar novas gerações, a reconstruir nossas instituições culturais e científicas, assumindo atitudes que necessariamente contornam e contradizem os sentimentos de decepção e desesperança dos dias presentes. Uma espécie de amor ao mundo, própria daqueles que sabem que o mundo, como alguém já disse, é um lugar muito bom para se viver, mas, lamentavelmente, muito mal frequentado.

Recebido em 20/05/2017 | Aprovado em I7/06/2017

José Reginaldo Gonçalves é PhD em antropologia cultural pela Universidade de Virginia, nos Estados Unidos, e professor no Programa de Pós-Graduação em Sociologia e Antropologia do IFCS/UFRJ. Desenvolve projetos de pesquisa sobre memória e cidade; patrimônios culturais; arquitetura e espaços; objetos, coleções e museus; teorias da cultura; história da antropologia. Publicou A retórica da perda: os discursos do patrimônio cultural no Brasil (3ed., 20I7), e organizou a coletânea de textos de James Clifford A experiência etnográfica: antropologia e literatura no século XX (4ed., 20II). 


\section{NOTAS}

I Em relação a essa abertura, não podemos deixar de mencionar aqui a contribuição significativa de outros pesquisadores, com destaque para a obra de Elide Rugai Bastos, que dedicou importantes estudos à obra de Gilberto Freyre (Bastos, I986; 2003; 2006).

2 Notadamente, "o excesso de natureza sexual" (Araújo, 2004: 56).

3 Comparando o éthos puritano e o confucionismo, diz Weber (1964: 235): "A true prophecy creates and systematically orients conduct toward one internal measure of value. In the face of this the "world" is viewed as material to be fashioned ethically according to the norm. Confucianism in contrast meant adjustment to the outside, to the conditions of the world".

4 "Considerada de modo geral, a formação brasileira tem sido, na verdade, [...], um processo de equilíbrio de antagonismos" (Freyre, 2004: II6).

\section{REFERÊNCIAS BIBLIOGRÁFICAS}

Araújo, Ricardo Benzaquen de. (20I7). Guerra y paz: Casagrande y senzala y la obra de Gilberto Freyre en los años 1930. Buenos Aires: Universidad Nacional de Quilmes Editorial. Araújo, Ricardo Benzaquen de. (2005) [1994]. Guerra e paz: Casa-grande \& senzala e a obra de Gilberto Freyre nos anos 30. 2 ed. São Paulo: Ed. 34.

Araújo, Ricardo Benzaquen de. (2004). Através do espelho: subjetividade em Minha Formação, de Joaquim Nabuco. Revista Brasileira de Ciências Sociais. São Paulo, I9/56, p. 5-I4. Araújo, Ricardo Benzaquen de. (1987). Totalitarismo e revolução: o integralismo de Plínio Salgado. Rio de Janeiro: Jorge Zahar. Bastos, Elide Rugai. (2006). As criaturas de Prometeu: Gilberto Freyre e a formação da sociedade brasileira. São Paulo: Editora Global.

Bastos, Elide Rugai. (2003). Gilberto Freyre e o pensamento hispânico: entre Dom Quixote e Alonso El Bueno. Bauru: Edusc. Bastos, Elide Rugai. (I986). Gilberto Freyre e a formação da sociedade brasileira. Tese de Doutorado. Programa de Estu- 
dos Pós-Graduados em Ciências Sociais/ Pontifícia Universidade Católica de São Paulo.

Borges, Jorge Luis. (2005). Outras inquisições. São Paulo: Companhia das Letras.

Bruford, W. H. (I975). The German tradition of self-cultivation: 'Bildung' from Humboldt to Thomas Mann. Cambridge: Cambridge University Press.

Freyre, Gilberto. (2004). Casa-grande \& senzala: formação da família brasileira sob o regime da economia patriarcal. 49 ed. São Paulo: Global.

Goldman, Harvey. (1988). Max Weber and Thomas Mann: calling and the shaping of the self. Berkeley: University of California Press.

Hughes, Stuart. (1975). History as art and as science: twin vistas on the past. Midway reprint. Chicago: The University of Chicago Press.

Mann, Thomas. (2016) [1924]. A montanha mágica. São Paulo: Companhia das Letras.

Montaigne, Michel de. (2016). Dos livros. In: Ensaios. São Paulo: Ed. 34 .

Simmel, Georg. (1988). Le concept et la tragédie de la culture. In: La tragédie de la culture. Paris: Petite Bibliotèque Rivages, p. I77-216.

Young-Bruehl, Elizabeth. (1982). Hannah Arendt: for the love of the world. New Haven \& London: Yale University Press. Weber, Max. (2004). A ética protestante e o 'espírito' do capitalismo. Edição de Antônio Flávio Pierucci. São Paulo: Companhia das Letras.

Weber, Max. (1964). The religion of China. New York \& London: A Free Press Paperback \& Macmillan Publishing Co. Inc. 


\section{UM AMIGO DO MUNDO}

Resumo

O texto traça um breve perfil intelectual e biográfico de Ricardo Benzaquen de Araújo (I952-20I7), historiador, sociólogo e antropólogo brasileiro recentemente falecido.

\section{A FRIEND OF THE WORLD}

Abstract

A short intellectual and biographical profile of Ricardo Benzaquen de Araújo (I952-20I7), a Brazilian historian, sociologist and anthropologist recently deceased.
Palavras-chave

História intelectual;

biografia intelectual;

autores brasileiros;

sociologia e antropologia;

Ricardo Benzaquen de Araújo.

\section{Keywords}

Intellectual history;

intellectual biography;

Brazilian authors;

sociology and anthropology;

Ricardo Benzaquen de Araújo. 